Orbis Tertius, vol. XXII, n 25, e033, junio 2017. ISSN 1851-7811

Universidad Nacional de La Plata

Facultad de Humanidades y Ciencias de la Educación

Centro de Estudios de Teoría y Crítica Literaria

\title{
El que calla, otorga: relatos encriptados de la post-dictadura en iBernabé, Bernabé! y El desierto y su semilla
}

\author{
Diego Hernán Rosain * \\ * Universidad de Buenos Aires, Argentina
}

\section{PALABRAS CLAVE}

post-dictadura

Río de la Plata

ocultamiento

novela histórica

alegoría

\section{KEYWORDS}

Post-dictatorship

Río de la Plata

concealment

historical novel

allegory

\section{RESUMEN}

Muchos de los escritos más importantes que se han producido durante los periodos de dictadura en América Latina han hecho uso de mecanismos de ocultamiento que les permitieron eludir tanto la censura como la denuncia directa. Dichos procedimientos que surgieron gracias a un contexto hostil y peligroso de producción siguieron manteniendo vigencia en las décadas posteriores a la finalización de los gobiernos de facto. En el caso del Río de la Plata en particular, ese tipo de escritura ha ganado cierto prestigio y se ha convertido en un lugar común a la hora de producir textos que traten los problemas y los daños que los regímenes dictatoriales han legado a los pueblos.

\begin{abstract}
Many of the most important writings that had been produced during dictatorship periods in Latin America have included mechanisms of concealment that allowed them to elude both censorship and direct denounce. This mechanism, which emerged thanks to a hostile and dangerous production context, remained active in the subsequent decades when the de facto governments came to an end. In the case of the literature of the Rio de la Plata, that type of writing gained certain prestige, but at the same time it became a cliche when producing texts about the problems and injuries dictatorial regimes have left as legacy.
\end{abstract}

Cita sugerida: Rosain, D. H. (2017). El que calla, otorga: relatos encriptados de la post-dictadura en ;Bernabé, Bernabé! y El desierto y su semilla. Orbis Tertius, 22(25), e033. https://doi.org/10.24215/18517811e033 


\section{Introducción}

Las series de dictaduras que se produjeron a lo largo del siglo XX en toda Latinoamérica dejaron grandes y profundas heridas en las conciencias de los pueblos afectados. Al final del siglo pasado, cada nación buscó los métodos y caminos para hacer frente al horror y al vacío que las repercusiones de los sucesivos golpes de Estado arrastraron aún hasta nuestros días, sin que existiera garantía alguna de restablecer la confianza en la democracia y las viejas instituciones políticas.

Durante los periodos de facto, la literatura utilizó y desarrolló diferentes tipos de herramientas textuales que le permitieron hablar de las realidades sociales vigentes sin aludir a ellas de manera directa. Si bien el silencio, el sobreentendido y el escamoteo de información no resultan un recurso novedoso dentro de la literatura, a fines del siglo XX estos eufemismos han encontrado un espacio fructífero en un momento en que la memoria colectiva era capaz de desentrañar los mecanismos de ocultación detrás de textos que buscaban ser decodificados. ${ }^{1}$ Este tipo de literatura evitaba, por un lado, poner en riesgo a los escritores que la producían y, a su vez, trazar una barrera que separara al público en, por una parte, aquellos capaces de detectar los mecanismos de asimilación y, por otra, aquellos más ingenuos incapaces de divisarlos.

En nuestros días, las escrituras de la post-dictadura o del retorno de la democracia, entendidas como una serie de textos que reflexionan y vuelven constantemente a los problemas y debates abiertos a causa de las políticas impulsadas por los gobiernos de facto durante la década del '70 en toda América Latina, le deben mucho a aquellos ejemplos furtivos del pasado. Esto es así porque, aun cuando los riesgos ya no son tales y las denuncias pueden hacerse de manera explícita, los escritores continúan escogiendo aquellos medios marginales o bien tangenciales para hablar de las masacres políticas llevadas a cabo por las fuerzas armadas con el fin de evocar y apelar en los lectores aquella memoria colectiva que sigue vigente hasta nuestros días. Con estos métodos se logra sortear dos peligros: primero, recaer en una denuncia simplona y poco efectiva; segundo, incurrir en una escritura quejumbrosa y emotiva que apele directamente a los sentimientos o experiencias personales del lector. $\underline{2}$

En el presente trabajo analizaré cómo los dispositivos de la novela histórica en ¡Bernabé, Bernabé! de Tomás de Mattos y el discurso alegórico en El desierto y su semilla de Jorge Barón Biza comparten recursos que les permiten, a partir de la configuración de realidades distantes y sin relación (aparente) con los debates públicos de su época, discutir y poner en cuestionamiento la situación presente en el Río de la Plata.

\section{La Historia escrita por los vencidos}

En el ensayo de Noé Jitrik, Historia e imaginación literaria, el crítico propone una aproximación a la novela histórica por lo que su nombre supone: un oxímoron. Si tenemos en cuenta los discursos de cada una de las partes, podríamos decir, por consenso general al menos, que el discurso histórico estaría ligado a un afán de verdad, mientras que el discurso novelístico estaría más del lado de la falsedad. Sin embargo, lo que Jitrik demuestra es que, aún en sus intentos por desentrañar verdades objetivas e irrefutables, la Historia no hace más que dar una mirada subjetiva sobre los hechos que narra. Todo intento del discurso histórico por hilvanar una serie de causas y consecuencias para generar una lectura coherente del transcurso de determinados sucesos supone una toma de decisiones y posturas políticas que se revisten con una opaca película de neutralidad. Mientras que, por el lado del discurso novelístico, no podemos afirmar que aquello que se dice pueda ser valorado en términos de verdad o falsedad ya que la ficción no pertenece al ámbito de lo real, sino que crea su propio mundo donde las cosas que se enuncian simplemente suceden en otro ámbito ajeno al plano de lo mundano.

La novela histórica es, en una de sus variantes, revisionista y a la vez genética: envía su foco de atención hacia el pasado para comprender el presente de la enunciación. Pero, en aquellos espacios donde las fuentes 
son escasas, los recursos limitados o los testimonios contradictorios; cuando a los novelistas no les alcanza el saber adquirido en el discurso histórico corriente a los fines de la escritura narrativa, es allí, en esas grietas y vacíos, donde se filtra la ficción. La ficción no llega para opacar el discurso histórico, sino para enriquecerlo; por medio de la ficción el novelista logra, como en el caso de ¡Bernabé, Bernabé!, aportar nuevas apreciaciones, conjeturas y valoraciones que de otra forma no podrían obtenerse. Donde se detiene el discurso histórico, comienza el de la ficción. $\underline{3}$

La novela histórica del escritor uruguayo Tomás de Mattos no solo pone a discutir los planos de la realidad y de la ficción, sino que los multiplica e intercala. De Mattos traza para su novela una serie de fechas clave que van desde la dictadura uruguaya de 1973, pasando por la Segunda Guerra Mundial, la Guerra de la Triple Alianza y el asesinato de los charrúas, hasta desembocar en las masacres de la conquista de América. Esta concepción de la Historia como cíclica es construida por el autor material y el prologuista y la autora ficticios, lo cual permite narrar el presente desde cualquier otro punto del pasado. Desde el comienzo, el lector tiene marcas explícitas del artificio narrativo y eso lleva a una de las hipótesis más fuertes de la novela: la Historia no solo se repite, sino que siempre está mediada por el discurso del otro; acceder de manera directa a los hechos resulta imposible tanto para el historiador como para el novelista. De Mattos habla a través de M. M. R., quien a su vez accede a la Historia por medio de Josefina Péguy, quien asimismo sólo puede estudiar la figura de Bernabé Rivera por medio de los testimonios de aquellos que lo conocieron en vida. La dificultad de los testimonios es que se encuentran no solo plagados de prejuicios, sino también de intereses mezquinos, versiones opuestas y dobles interpretaciones. A esto se le deben sumar las observaciones y reflexiones que realiza la autora ficticia, quien está más cerca de la sensibilidad del lector que de la de sus contemporáneos.

Si la Historia tiene la particularidad de "restablecer el lazo entre lo colectivo y lo individual, que un pensamiento no histórico disocia” (Jitrik 1995: 16), en la novela de de Mattos el personaje que permite la construcción de dicho lazo es sin duda Bernabé Rivera. Él es la clave para comprender no sólo la aniquilación de la población charrúa, sino también los asesinatos políticos durante la dictadura militar. La historia de los Rivera, tanto la del tío como la del sobrino, muestran la tragicidad de las empresas aparentemente heroicas impulsadas por el Estado. ${ }^{4}$ Toda acción militar que lleva a cabo el Estado no es en pos de la paz ni de la seguridad nacional, sino a favor de los intereses individuales, con la esperanza de que algún día (quizás demasiado pronto) esas acciones puedan ser redimidas. $\underline{5}$ Sin embargo, Josefina no permite que los criminales salgan impunes. Sus palabras son tajantes y terminantes con respecto a las responsabilidades del Estado y sus subordinados frente a los actos cometidos. $\underline{6}$ Su misión es la de derrocar los grandes mitos nacionales para devolverles su densidad histórica, su humanidad y, sobre todo, su mundanidad. De Mattos critica las empresas estatales del siglo XIX, pero sus dardos se dirigen indirectamente al siglo XX.

Josefina no sólo defiende a los charrúas, sino que también se compadece (en el sentido de corresponderse y estar en consonancia con ellos): la violencia de la que los charrúas han sido víctimas por parte del Estado, ella la ha padecido de primera mano por parte de los hombres que la han subyugado por su rol social, determinado a su vez por su sexo biológico. Josefina, una mujer dedicada a la escritura de ficciones y que no puede mantenerse callada y al margen de los acontecimientos, encuentra mayor afinidades con esta comunidad de salvajes que con su seno elitista y terrateniente. ${ }^{7}$ Sin embargo, dentro de las posibilidades que plantea la novela de de Mattos también se encuentran sus límites. Josefina jamás dice cuáles son las garantías que le permiten hablar como "vocera" del pueblo charrúa, pero tampoco es esa su misión dentro del relato. Ella se dedica menos a proteger la integridad del pueblo charrúa que a levantar cargos contra el Estado, y esto se debe al simple hecho de que ya no quedan víctimas a las cuales defender; apelar a un hábeas corpus 
es inútil una vez que los acusados se convirtieron en cadáveres que flotan en la mansa corriente del río. Desde esta apreciación de la historia, se demuestra cómo las farsas emprendidas por el Estado desencadenan una tragedia masiva a nivel social.

\section{Lecturas literales y alegóricas}

Desde Esopo y Platón hasta nuestros días, la alegoría ha sido un recurso textual que proporcionó métodos y variantes para acceder a diferentes tipos de saberes que, de otro modo, habrían sido más difíciles de recuperar. La alegoría consiste en volver conocido aquello que se desconoce parcial o completamente, es una simplificación, una reducción del objeto a elementos de lo cotidiano para que así el destinatario pueda comprender con mayor facilidad aquello que se le intenta transmitir. Esto no significa que la alegoría sea un mero juego de comparaciones; por el contrario, lo que busca es partir de un punto familiar para que el lector pueda desandar su propio camino a la interpretación.

Para Ricardo Campa, "la alegoría es, sin embargo, el énfasis del detalle, una aproximación de contrasentidos para resultados breves e inmediatos. Todo lo que se representa en la escena del mundo se puede reducir al efecto ejemplar de una circunstancia, y en este sentido la alegoría baja de tono la vida para dejar incontaminado el reino de la realidad” (1971: 544). La alegoría implica la existencia de, por lo menos, dos sentidos para las mismas palabras: uno literal y uno metafórico. Este doble sentido debe estar indicado en la obra de manera explícita, es decir, no depende de la interpretación del lector aunque sólo se llegue por medio

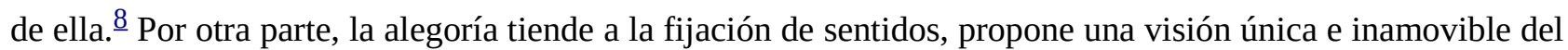
universo. El sentido alegórico es propio de escritos con una finalidad moralizante, es por ello que pertenece al grupo de los géneros didácticos; pero también es un género epistemológico, permite comprender y conocer mejor el mundo. $\underline{9}$

Podría argüirse que Barón Biza es un escritor realista por el hecho de que su obra El desierto y su semilla parte de un suceso real (aunque pareciera provenir del mundo de la ficción). Sin embargo, a lo que el lector asiste desde el comienzo es a una ficcionalización de la historia personal del autor. A diferencia de lo que ocurría con ¡Bernabé, Bernabé!, en la novela de Barón Biza no hay un afán por iluminar con "verdades” la percepción del lector; sino que, por el contrario, se le escatima información: desde su propio nombre hasta su parentesco con los personajes, el narrador de Barón Biza es un encubridor; trata de ocultar su verdadera identidad y su linaje para así no verse directamente relacionado con esos seres que detesta. Pero ya veremos que hay otros matices.

El siniestro ocurrió en 1964, mientras que la novela es previa a 1995 y recién llega a publicarse en 1998. Treinta años de diferencia hay entre una fecha y otra, tiempo necesario para tomar distancia y reflexionar acerca de lo ocurrido; pero aún hay más. Luego, el suicidio del padre al otro día del crimen y el de su madre en 1978; queda otra fecha que nos interesa sobremanera: entre 1976 y 1983 tiene lugar en Argentina el último de los golpes militares liderado por el teniente general Jorge Rafael Videla. Es decir, a tres décadas del crimen familiar y a una del político, Barón Biza encuentra similitudes y paralelismos entre un hecho y otro.

El personaje de Eligia pierde desde el comienzo su individualidad; es una cara sin rostro y, para utilizar el término de Deleuze y Guattari, un cuerpo sin órganos: "no se puede conseguir, nunca se acaba de acceder a él, es un límite. Se dice: ¿qué es el CsO? — pero ya se está en él, arrastrándose como un gusano, tanteando como un ciego o corriendo como un loco, viajero del desierto y nómada de la estepa” (2002: 156). Eligia es un límite: límite de lo real, de lo inteligible, de lo comprensible y del ser. Eligia ha dejado de ser Eligia; $\frac{10}{10}$ ahora es una huella, un fantasma, una sombra del pasado, y lo único que pueden hacer los médicos es devolverle un rostro, pero no el suyo, sino otro. 11 El rostro es aquello que encierra tanto la historia familiar 
como la historia política a nivel nacional y mundial; penetrar en él implica tener acceso al conocimiento de los hitos más atroces de los sucesos políticos del siglo XX. $\underline{12}$

Eligia es, por un lado, la personificación de Milán, la cual “ya habían empezado a reconstruirla antes de que terminara la guerra” (1998: 203). Eligia es la momia egipcia que vive entre los escombros del bombardeo y que tanto asustaba a Mario de niño, pero también, dentro de esta yuxtaposición de metáforas, es el reverso de Evita, su némesis y contrapartida: Eligia es el zombie, la muerta en vida o la no muerta masacrada de los radicales, mientras que Evita es el cadáver beatificado y la niña eterna de los peronistas. $\frac{13}{2}$ Lo que tienen en común las tres, es la violencia política que se ha ejercido sobre ellas: representan a las naciones destrozadas por los movimientos de derecha y la represión armada tanto de Italia como de Argentina. Esos nuevos seres, esas ruinas, son el producto de una violación salvaje de hombres que representan y simbolizan las guerras y las dictaduras alrededor del mundo.

Los personajes masculinos en la novela de Barón Biza no son figuras positivas. Arón, el violador de Dina, el padre de Sandie que le extiende una invitación a un prostíbulo al narrador e incluso el mismo Mario, que termina realizando un corte en el rostro de Dina simulando el acto de su padre, son seres nefastos y cínicos. Son los artífices de las escenas de sufrimiento más cruentas que se llevan a cabo por el simple hecho de hacer el mal. El limpio discurso de los médicos tampoco es muy diferente. Con falsas promesas y palabras vacías avalan y apoyan el cambio mientras hacen borrón y cuenta nueva, omitiendo cualquier referencia o juicio sobre el pasado inmediato. Los médicos simbolizan a las instituciones burocráticas mientras que Arón ocupa el lugar de las Fuerzas Armadas: en ambos se prefiguran la corrupción de las ideologías de la década del '60.

Así como en ¡Bernabé, Bernabé! se pueden rastrear los orígenes y las repeticiones del presente en el pasado por medio de la historicidad, en El desierto y su semilla esta lectura es posible gracias a varios factores. Uno de ellos es el recorrido que se traza por todas las guerras y persecuciones políticas que se enumeran a lo largo de la novela, las cuales, a diferencia de la novela de de Mattos, no son retrospectivas, sino recursivas en la línea de tiempo histórica. Los portavoces de estas historias son los ciudadanos, como la Tía de Dina que narra los horrores del bombardeo de Milán.

La Historia está ligada al presente de la narración de la novela y es por eso que puede brindarse una lectura historicista de la misma, pero aún hay otro elemento que ofrece esta interpretación: el cuadro de Arcimboldo. Para describir el cuadro del milanés, el narrador utiliza los mismos métodos técnicos que usa para el norostro de Eligia. Sin embargo, encuentra en él dos posibles lecturas, dos sensaciones opuestas que se entremezclan. Es un jurista (lectura alegórica), pero a la vez es un montaje de libros, pollos y pescados que construyen un cuerpo (lectura literal). Como afirma María Soledad Boero, es a través del rostro donde se conectan las potencias de la naturaleza y donde el escritor puede componer esas zonas indiscernibles entre lo humano y lo inhumano, el horror y la violencia de la destrucción creativa. $\frac{14}{}$ El desierto y su semilla es una alegoría sobre los procesos nacionales de reorganización impulsados por los múltiples gobiernos de facto del siglo XX que condujeron a una restructuración de los pueblos y las ciudades a nivel mundial por medio de la violencia física. $\underline{15}$

Entonces, ¿qué lugar ocupa Mario en esta fórmula? El de la generación que sobrevive al horror. Eligia, la Nación, se suicida porque no puede tolerar las incontables pérdidas, los efectos de la reconstrucción. Ese rostro se vuelve demasiado pesado para un solo cuerpo y es por eso que el final es previsible y se finiquita en una única frase al pasar. La alegoría "se detiene en la constatación de un orden de pensamientos" (Campa 1971: 548); ese orden que registra El desierto y su semilla es apocalíptico e irremontable: el del vacío producido por la violencia política. 
La anciana que habla hacia el final es una ilusión, una imagen completa de la nación que se busca y se persigue, una idealización de la argentinidad que no llega a representar la realidad, sino más bien una fantasía a la cual Eligia no puede acceder. Es Mario, con todo su pesimismo y su pasado, quien deberá reponerse para salir a flote del vacío. Pero, como sabemos, el autor termina por suicidarse; ¿ocurrirá lo mismo con Mario?

\section{El desierto y su trascendencia}

El desierto ha sido pensado como una hoja en blanco que permitió la aparición de la ficción a lo largo del siglo XIX. Su inmensa productividad discursiva logró disparar reflexiones y polémicas de todo tipo. Para Fermín Rodríguez, "el desierto argentino es menos una geografía concreta que un espacio capaz de alimentar por siglos las fantasías de viajeros, naturalistas, políticos, militares y escritores” (2010). El desierto fue, en definitiva, más una construcción textual que un hecho fáctico.

Antes que él, América se transformó en el mapa a ser trazado por las fantasías de los conquistadores europeos. En nuestros días, las villas miseria y las favelas son las zonas no cartografiadas, donde el tejido urbano se interrumpe, las calles no tienen nombre y no todo el mundo puede entrar o incluso salir. Estas zonas vacías, por descubrir e incorporar, permiten a lo largo de la historia no sólo definir la propia identidad por medio de la negatividad y la confrontación, sino que nombran menos una localización de lo geográfico antes que una dimensión de la imaginación de lo social y lo cultural. Sin embargo, existe una gran distinción.

Con el correr de los siglos, las identidades comunales se han multiplicado, diversificado y restringido infinidad de veces. Los límites de estas pueden variar en mayor o menor medida ya que, como analiza Anderson, "se imagina limitada porque incluso la mayor de ellas, que alberga tal vez a mil millones de seres humanos vivos, tiene fronteras finitas, aunque elásticas, más allá de las cuales se encuentran otras naciones” (1993: 24-25). América, así también como Oriente antes que ella, funcionó hasta el período de las revoluciones independentistas como la contracara de Occidente, el valor opuesto que legitimaba y construía su identidad como comunidad hegemónica. Posteriormente, cuando las naciones jóvenes debieron erguir sus propios héroes y mitos, tomaron al desierto como aquella zona poblada por el otro, el salvaje, el ser extraño que no formaba parte de la comunidad y que debía ser recuperada. Hoy, son las villas y las favelas las zonas relegadas y excluidas. Todo esto apunta a dos conclusiones: por un lado, el otro siempre comparte un territorio determinado con la comunidad a la cual se opone, ya sea a nivel mundial, nacional o municipal; por otra parte, el otro siempre habita un espacio cuya legalidad y normativa no coinciden con la comunidad hegemónica, la cual, a su vez, no puede tener acceso completo a ella y es por eso que debe recurrir a elementos diversos, entre ellos la ficción, para lograr materializarla, comprenderla o someterla.

Tanto ¡Bernabé, Bernabé! como El desierto y su semilla optan por el desierto como espacio imaginario para producir la ficción. Esto implica un enorme esfuerzo por reconstruir este tópico que, al momento en que los escritores producen sus novelas, cuenta con una larga tradición: el desierto ya es una geografía subyugada e incorporada a los límites nacionales. Empero, es justamente porque ambas novelas cuestionan la idea de la nación como una entidad uniforme y completa que escogen al desierto, el espacio del siglo XIX, y no las villas de fines del siglo XX como campo de batalla y metáfora para desarrollar la ficción. La elección por el desierto supone, entonces, un revisionismo histórico y una crítica a la imagen presente que se ha construido en torno a las naciones argentina y uruguaya, cuyos orígenes confluyen no solo en la disputa territorial con los aborígenes.

Esto se ve claramente en la novela de de Mattos, en la cual los conflictos por la tenencia de las tierras es lo que desencadena la masacre antes que las diferencias identitarias:

Mi padre insistía que la alianza con los indios, fue "muy circunstancial y azarosa”. Los 
objetivos de ambos pueblos no solo eran distintos, sino incompatibles. Para los charrúas, la libertad era la perduración del Desierto: tierra sin cultivar, ganado sin cuidar, barbarie compartida. Para nosotros, la libertad era la posibilidad irrestricta de que cada ciudadano volcase el mayor esfuerzo para el progreso de su familia, amparado por las máximas seguridades de que serían solo suyos los legítimos frutos de su esfuerzo. "Civilización, Josefina; civilización repartida entre todos, según sus talentos” (1992: 56).

El Estado, enarbolando la bandera del progreso y la expansión del afán civilizatorio, justifica los actos descarnados y traicioneros que llevará a cabo hacia el final de la novela y que ya son bien conocidos por todos como consecuencia de una incompatibilidad y desacuerdo entre las partes afectadas, cuando dentro del mismo discurso del padre de Josefina ya se deja entrever que lo único que lo motiva son la producción agraria y los beneficios económicos que pueden brindarles esas tierras. Llevada al plano de la enunciación, la novela de de Mattos denuncia los abusos e intereses mezquinos del gobierno de facto uruguayo a la vez que devela sus mecanismos de ocultamiento y sus mensajes implícitos. Se ve así cómo la novela de de Mattos gira completamente en torno a los silencios y escamoteos, tanto a nivel de la forma como del contenido: un relato que habla con y sobre eufemismos.

El caso de la novela de Barón Biza es otro. Como ya vimos, Eligia representa a la nación que ha sido destruida para luego ser reparada desde sus cimientos. El desierto sería, dentro de las etapas de reconstrucción, la primera que atraviesa el cuerpo sin rostro de Eligia; representa el lienzo, la materia prima, el terreno vacío, el mármol que hay que machacar y cincelar para dar forma a la obra de arte. El desierto es el punto de partida, el origen de la vida y, paradójicamente, la carencia de la misma: "Las corrientes de ácido se manifestaron con taimado retraso, moldeándose sobre la carne, erosionándola, transmutando la vida en geología, [...] un trazo de la actividad volcánica, que aparecía ya enfriada y con pretensiones de eternidad, estable, fija e inexpresiva como el desierto" (1998: 24). Pero, además, el desierto, lo rocoso, lo tectónico, están ligados a la idea de mal, tanto como esencia así como la ejecución de un acto malvado:

Pero la idea de que lo caótico es más tolerable que lo desértico [...] quedó sembrada en mi conciencia de aquellos años: la idea de que el mal no era un tema al alcance de la voluntad, que si alguna vez afectaba al hombre (con menos frecuencia de lo que su orgullo lo suponía) era bajo la misma condición que tiene en la naturaleza: involuntario, total y ausente, como en los desiertos de rocas (1998: 31).

Es decir, antes incluso de que se cometieran los actos de violencia, el terreno ya se encontraba invadido por una maldad insondable. La nación no sólo se funda con un crimen, sino también en un espacio regido por un mal natural, orgánico. La semilla del desierto es, en este sentido, una aberración que va en contra de cualquier lógica o ley natural. Mario es el fruto de la violación del Estado (Arón) al terreno rocoso, infértil, a la promesa de una Nación (Eligia); la idea de una descendencia desértica es un hecho contranatura. Mario, como producto o como resabio de esa relación, está condenado, pertenece a una generación cuyo origen la delata y marca su destino fatal.

\section{La familia es lo primero}

Si tuviéramos que reducir ambas historias a su mínima expresión narrativa, encontraríamos que en su trasfondo y motivación hay dos trifulcas familiares. Los sostenes del relato son Josefina y Mario, dos sujetos que buscan escapar a los roles de hijo que sus padres esperan que cumplan. Josefina forma parte del seno de familias adineradas y poderosas que manejan el destino de la nación uruguaya durante el siglo XIX; con el transcurso de los años se ha quedado sola, sin padre ni marido que la protejan, pero tampoco que la censuren. Mario, en cambio, odia a su padre y todas sus fuerzas están dirigidas a ser su imagen inversa; con su madre mantiene una relación cercana pero frívola ya que, si bien la acompaña durante todo su tratamiento, oculta 
frente al resto el hecho de que ella sea quien es. El punto es que no se tratan de familias disfuncionales ni en las cuales priman episodios de incesto o adulterio: son linajes donde lo primordial es el odio o la inconformidad frente a los progenitores y a las figuras de autoridad. En cualquier caso, los lazos afectivos se han visto drásticamente comprometidos gracias a las diferencias generacionales, lo cual impide la concreción de cualquier expresión amorosa.

Josefina, ya se encarga de dejarlo bien en claro el prologuista ficticio M. M. R., es una mujer rebelde para lo que podía considerarse como tal en la sociedad uruguaya de mediados del siglo XIX. Si bien su objetivo se limita a dar información acerca de la vida y muerte del coronel Bernabé Rivera, en el transcurso y gracias a que la reconstrucción de los hechos requiere de la recopilación de testimonios de parientes y conocidos muy cercanos a su entorno para dar cuenta de lo que realmente sucedió, Josefina no puede dejar de mostrar su desaprobación y desprecio frente a las opiniones y juicios de su padre, por un lado, los del sargento Gabiano, amigo y hacendado de la familia, y los de su esposo Juan Pedro Narbondo, por el otro. Josefina es una mujer demasiado inquisidora y denunciante; no se adecúa a los parámetros femeninos de la época y eso le vale la sanción y el reproche de las figuras masculinas que la rodean. Sin embargo, Josefina es la única que los sobrevive a todos y es por eso que puede tomar la palabra final sobre el asunto de la masacre de los charrúas y hacer lo que le plazca con los discursos de los difuntos.

Mario, al igual que Josefina, es escritor. Eso es lo único que comparte con su padre el cual fue autor de múltiples episodios de violencia hacia a su familia. Mario desea desprenderse de toda pertenencia o recuerdo de su padre, pero siempre está su madre allí, como última voluntad de la locura paterna, para recordarle de dónde proviene y hacia qué está condenado a convertirse. Sus hermanos apenas aparecen aludidos en determinados momentos: el mayor es el encargado de administrar la empresa y la fortuna familiar, mientras que la menor es demasiado pequeña como para hacerse cargo de todo lo que está ocurriendo. Como una obviedad, un mandato mudo, Mario debe encargarse del cuidado de Eligia, la cual se ha convertido en una sombra de lo que alguna vez fue, el reducto de un cuerpo cuya historia debe volver a contarse.

Sería pertinente preguntarse entonces qué importancia o interés tienen las historias personales de estos dos sujetos para los problemas y debates que atraviesan las comunidades que conforman. La respuesta está en que la historia familiar está estrechamente ligada a la realidad nacional. Es imposible disociar una de otra ya que la familia funciona, en los mundos que configuran estas ficciones, como un modelo a pequeña escala de los males que atraviesan al país o bien como clave de lectura para comprender lo que en verdad ocurre. La identidad Familia-Nación propone a la familia como célula que refracta (y representa) contradicciones y rasgos de un contexto mayor. La perversión de esta dinámica familiar se sustenta en la violencia que ejercen los progenitores sobre sus vástagos para satisfacer secretos deseos de dominio irracional y la necesaria reacción violenta de los hijos hacia los padres como único medio de alcanzar una dudosa liberación.

El relato de Josefina muestra cómo la elite uruguaya se reúne para debatir asuntos políticos cuya resolución definirá el destino de la nación, ya sea para bien o para mal, pero siempre protegiendo los intereses personales de la temprana oligarquía regional. La política se vuelve así un asunto que concierne no al pueblo, sino a un grupo de individuos que ostentan el poder con displicencia pero sin dudar en generar los exterminios más atroces en vistas de unos pocos favores.

La experiencia del autor de El desierto y su semilla está relacionada con la política nacional porque sus padres fueron figuras públicas. Su padre fue escritor y militante de la UCR, con vaivenes y tratos tanto con la izquierda como con la derecha; su madre, cuyo padre fue también un político radical y gobernador de la provincia de Córdoba, fue una activista de los derechos de la mujer, perseguida política y presidenta del Consejo Nacional de Educación. El escándalo sin precedentes se dio a conocer en todos los medios y captó el interés del público de inmediato. Jorge Barón Biza no pudo sino ver un contacto llamativo entre los 
personajes públicos y los privados y consiguió, con gran astucia y serenidad, distanciarse de su rol de hijo para privilegiar al escritor y cronista. Logró ver en esa demostración de violencia doméstica la brutalidad de un país que se destruía a sí mismo con la excusa de reconstruirse.

La familia es la célula básica de la sociedad, incluso antes que el individuo, porque es el punto institucional de anclaje del sujeto con el conjunto de las demás instituciones. Describir la institución familiar permite profundizar en la psicología de los personajes y en los tipos de relaciones que entablan. La familia, concebida como la más primitiva de las comunidades e instituciones, es la primera que preserva a los sujetos de cualquier tipo de peligro, la que los ayuda en su evolución y en su crecimiento; pero también la que intentará controlarlos, moldearlos y reprimir sus deseos. Es por eso que entabla ciertos paralelismos con la institución estatal y se convierte así en el ámbito idóneo para narrar ciertas historias, valga la redundancia, de la Historia.

\section{Conclusión}

Los mecanismos de ocultamiento, los silencios provocadores, los análisis históricos lejanos al presente de la enunciación, los asuntos marginales y secundarios y los temas en apariencia banales o triviales parecieran ser cuestiones afines a las escrituras post-dictatoriales. Es que, lo que había funcionado como una herramienta fructífera durante los períodos de gran represión política, intelectual y artística, se convirtió con el regreso de las democracias en un discurso no solo consagrado, sino también erudito.

Las escrituras de la post-dictadura no suponen la utilización de las viejas formas y estrategias utilizadas durante los gobiernos de facto como mera repetición, sino que suponen una filiación y un compromiso con los debates previos y posteriores a dichos momentos, con el legado de aquellos exiliados o caídos durante la batalla por la libertad de expresión y de pensamiento que excede los límites de las fronteras nacionales para convertirse en una sensibilidad latinoamericana de percepción del horror político.

En definitiva, estas novelas muestran con el escamoteo, revelan con el camuflaje y dicen con el silencio más de lo que aparentaría una lectura rápida e ingenua de las mismas. Debemos ver más allá de las máscaras para poder devolverles su sentido siempre vigente.

\section{NOTAS}

1 "La memoria colectiva aparece como un emergente de la dinámica grupal, como una construcción intersubjetiva, que no está exenta, desde esta perspectiva, de un carácter normativo al generar marcos de referencia para la orientación de las conductas de los actores sociales.

Cuando la naturaleza del lazo social comienza a ser atravesada por la heterogeneidad, la explosión de la diversidad y la necesidad de reconocimiento a partir de la diferencia el sustrato mayoritariamente general y universalizante de la memoria colectiva se empieza a corroer. El formato del Estado-nación ya no contiene colectividades homogéneas, ni relatos únicos; hay una pluralización de los sentidos de pertenencia y de los horizontes de expectativas" (Makowski 2002: 146-147).

$\underline{2}$ "En el plano privado, individual, la memoria es una suerte de estado afectivo, fluye como recuerdo, como relato que puede contribuir a suturar el presente del pasado. Cuando la memoria se desplaza hacia la esfera pública, cuando su carácter es del orden de lo social, puede reificar ciertos sentidos del pasado, potenciar olvidos, disolver sujetos y grupalidades; o bien, generar un trabajo de recodificación del pasado con vistas a una mayor democratización y extensión de una cultura de los derechos humanos” (Makowski 2002: 147).

$\underline{3}$ “La particular focalización de varias novelas históricas en el siglo XIX obedece, en parte, a este intento por 
buscar un origen de la dictadura militar en el trágico siglo pasado. ¡Bernabé y Bernabé! resulta paradigmático al presentar el etnocidio de los charrúas como una historia en la que van emergiendo signos característicos del último gobierno militar; la ética militar de la obediencia debida y la teoría de la aniquilación, el problema del juicio, la importancia de la memoria, articulados alrededor del eje de la crisis y búsqueda de identidad” (Basile 1996: 4).

4 “Josefina Péguy y Federico Silva coincidirán muy pronto, en las primeras líneas de la carta a la que ya dejo lugar, y categorizarán a Bernabé Rivera como un héroe de estirpe homérica. Permítaseme despedirme con una acotación: yo optaría por convocar el espíritu más compasivo de Sófocles. La culpa del sobrino de don Frutos me parece tan intelectiva como la de Edipo, aunque su delito, como tantos del presente, no sea un parricidio, sino un fratricidio. Creo que su transgresión de los límites del orden último del mundo tiende a centrarse, como en el atribulado y fugitivo rey de Tebas, en el cultivo exacerbado de unas pocas virtudes que el implacable y disciplinado coronel persiguió con saña” (de Mattos 1992: 26).

$\underline{5}$ "Independientes pero ligadas, las naciones se conectan en un vínculo comparable al que se establece entre parientes. Aun cuando emprendan entre sí la más sangrienta de las guerras, éstas se entenderán eventualmente como 'guerras fratricidas': como en las peleas entre hermanos, las luchas nunca concluyen en la total aniquilación del adversario; el paso del tiempo restablece el curso normal de las relaciones [...]. El desplazamiento de significado alude al mecanismo de olvido/recuerdo que simultáneamente sostiene la identidad nacional y naturaliza su violencia constitutiva. La noción de fratricidio deviene una herramienta eficaz de 'colonialismo interno'. En otras palabras, señala Anderson, el fratricidio no es en este contexto específico otra cosa que la resemantización del 'genocidio’” (Garibotto 2008: 110-111).

$\underline{6}$ "Creo que la historia (de Gabiano), por más simple que nos parezca, admite más de una lectura. La que más me afecta es la que me obliga a ver clarito lo que en otras ocasiones consigo que me pase desapercibido: el horror total de un hecho no es igual a la suma de los horrores menores, suscitados por cada uno de los actos necesarios para causarlo. Por eso, quien se negaría sin titubeos a ser su autor, puede aceptar — casi sin darse cuenta— ser uno de sus coautores” (de Mattos 1992: 65).

$\underline{7}$ "La novela se distancia de un "anacronismo deliberado" en tanto tiende a borrar las marcas del presente de T. de Mattos y desplazar la perspectiva crítica sobre la campaña contra los charrúas hacía Josefina y el editor, respetando la unidad temporal en que cada uno se sitúa. Para ello elige un personaje lo suficientemente excéntrico como para hacer verosímil su postura crítica: una mujer de carácter inquieto y enjuiciador que, en el ámbito doméstico y privado de una familia patricia, toma contacto con los hombres de la clase dirigente y con el archivo de su marido, referentes indispensables de la versión oficial” (Basile 1996: 7).

$\underline{8}$ "Los dos ritmos se entrelazan: uno, el de la realidad, restituye al otro, el de la fantasía; uno habla del otro, sin sobrentendidos. La alegoría lo evoca. Sus referencias a la realidad se alejan por la intensidad del enfrentamiento con el que las cosas se acercan a la conciencia. Esta se libera de toda hipoteca simbólica. Se devana en la narración, sin proponer un orden o una sucesión a las cosas. Es un apunte sobre las apariencias, aceptadas como tales, sin tener, pues, un significado. Y sobre esa falta de significados, la alegoría compromete el pensamiento con la falsa "perennidad» de las referencias, de las equivalencias y de las adjetivaciones” (Campa 1971: 544).

$\underline{9}$ “La alegoría es conclusión en sí misma. Ejercicio de narcicismo, exploración de las estructuras y de las regiones en las que se efectúan las transformaciones. La alegoría es la utopía de la estática; no condiciona la libre expresión de los pensamientos; los conduce en una sola dirección, en un intento de desnaturalizar, empequeñeciéndolo, el ímpetu creativo” (Campa 1971: 545-546).

10 "Después de tres meses, el único indicio todavía identificable era la nariz corta e insolente, que se había 
petrificado junto con las mejillas cóncavas. Una furia inmóvil de hielo herrumbrado se apeñuscaba en torno de ese antiguo rasgo, arqueología de una coquetería del pasado. Era la letra final de una identidad que se iba, azotada por olas de un nuevo perfil, inhumano [...].Al quitarle, en la última sesión quirúrgica, la punta de la nariz y la parte más blanda del cartílago, cayó el último baluarte que la hacía reconocible”, (Barón Biza 1998: 34-35).

11 "Como le advertí, no se trata de disimular, tapar, ocultar. Es necesario aceptar que ha estado inventada una nueva realidad. Su padre ha creado alguna cosa de nuevo. No podemos negarlo: entonces sólo nos resta darle a la tragedia su propia naturaleza, su camino para expresarse. Quitar las viejas ruinas, para que la nueva cara se forme en libertad, sin laberintos engañosos” (Barón Biza 1998: 82).

12 "La alegoría lleva al estado de conocimiento, ese grado de imprevisibilidad que es innato en la visión del mundo. El conocimiento parece hacerse por estratos, objetivación de detalles. La disantropomorfización es un proceso aparentemente abstractivo de la realidad. Una entidad privada de cualquier tipo de atributo, es decir, que no nos levase a un fenómeno no podría de ninguna forma referirse a la realidad. Lo inimaginable es impensable; el no ser es el límite más impreciso y efectivo de existir” (Campa 1971: 545).

13 "Finalmente, de las habitaciones que algunos ordenanzas llamaban con temor la 'clínica de la Eternidad', salió no ya la esposa del Presidente, sino una muñeca angelical: era ella sin duda, pero cuando tenía doce años, cuando su belleza había sido más perfecta, su piel más blanca e impecable y su alma no había sufrido todavía los desgarramientos de la política y la enfermedad. Por su parte, el gran sabio declaró a la prensa: 'Es un trabajo perfecto. Este cuerpo es imputrescible, eterno. Sólo lo podrían destruir el fuego o algunos ácidos.” (Barón Biza 1998: 111).

14 "Es esa misma falta de escala, ese anamorfismo psíquico que el narrador encuentra en la pintura de Arcimboldo, la que nos hace pensar entonces, en la herramienta simbólica del lenguaje como soporte para dar cuenta de ese rostro que ya dejó de ser rostro porque aparece conectado con otras potencias de lo natural, de lo que escapa a nuestras construcciones imaginarias y a nuestras percepciones más codificadas” (Boero 2008: 27).

15 La novela de Barón Biza insiste en este aspecto material de las violaciones políticas, tanto así que lo simbólico pasa a un segundo plano. Milán es destruida hasta los cimientos; el rostro de Eligia debe ser forzado en su reconstrucción. La coerción que los gobiernos de facto ejercen no está fundada en amenazas ni mentiras, sino que existe una verdadera violencia física, real, que implica una transformación radical.

\section{BIBLIOGRAFÍA}

Anderson, Benedict (1993). "Introducción”, en Comunidades imaginadas. Reflexiones sobre el origen y la difusión del nacionalismo (pp. 17-25), México, D. F., Fondo de Cultura Económica.

Barón Biza, Jorge (1998). El desierto y su semilla, Buenos Aires, Simurg.

Basile, Teresa (1996). “iBernabé, Bernabé! de Tomás de Mattos: Crisis y revisión de la identidad uruguaya”, en Orbis Tertius, $\quad\left(\mathrm{n}^{\circ} \quad 2-3\right), \quad$ pp. $185-210 . \quad$ Doi: http://www.memoria.fahce.unlp.edu.ar/art revistas/pr.2495/pr.2495.pdf

Boero, María Soledad (2008). "Sobre rostros caídos. La construcción de una estética en El desierto y su semilla, de Jorge Barón Biza”, en Cartaphilus (nº 3), pp. 20-30.

Campa, Ricardo (1971). “Alegoría y simbología”, en Cuadernos Hispanoamericanos (nº 255), pp. 543-552. 
De Mattos, Tomás (1992). ¡Bernabé, Bernabé!, Montevideo, Ediciones de la Banda Oriental.

Deleuze, Gilles y Félix Guattari (2002). “¿Cómo hacerse un cuerpo sin órganos?”, en Mil mesetas. Capitalismo y esquizofrenia (pp. 155-171), Valencia, Pre-Textos.

Garibotto, Verónica Inés (2008). “Del presente hacia atrás: ¡Bernabé, Bernabé! y la reformulación del relato nacional para la construcción de un presente democrático”, en Contornos en negativo: reescrituras posdictatoriales del siglo XIX (Argentina, Chile y Uruguay) (pp. 101-114), Pittsburgh, University of Pittsburgh.

Jitrik, Noé (1995). Historia e imaginación literaria. Las posibilidades de un género, Buenos Aires, Biblos.

Makowski, Sara (2002). “Entre la bruma de la memoria. Trauma, sujeto y narración”, en Perfiles Latinoamericanos, pp. 143-157.

Nuñez, Jorgelina (2010). “Fermín Rodríguez: ‘La ficción fundó el desierto’”, en Revista Ñ. Recuperado de: http://www.revistaenie.clarin.com/ideas/fermin rodriguez 0 379762056.html.

Varo Zafa, Juan (2006). Alegoría y metafísica. El problema de la alegoría en San Juan de la Cruz, Granada, Facultad de Filosofía y Letras de la Universidad de Granada.

Basile, Teresa (2005). "La condición de lo heroico en la posdictadura uruguaya”, en Revista Iberoamericana, Vol. LXXII, n² 213, Pittsburgh, octubre-diciembre, pp. 1203-1214.

Basile, Teresa (2000). "La figura del origen en la memoria posdictatorial”, en Inti. Revista de Literatura hispánica, vol. I (n51), pp. 31-51.

Link, Daniel (2001). “Un Edipo demasiado grande”, en Radar Libros, 16 de septiembre.

Saítta, Sylvia (1998). “El desierto y su semilla de Jorge Barón Biza o el derecho de escribir”, en Entrepasados (nº 14), pp. 185-196. 